\title{
Implementasi Algoritma K-Means Dalam Mengukur Tingkat Kepuasan Siswa Terhadap Pelayanan Sekolah Studi Kasus Di Mts.S Nurul Amaliyah
}

\author{
"Mhd. Gilang Suryanata, Deski Helsa Pane, Masyuni Hutasuhut \\ * Program Studi Sistem Informasi, STMIK Triguna Dharma \\ Email: suryanatagilang@gmail.com
}

\begin{abstract}
Abstrak
Memberikan pelayanan terbaik adalah salah satu cara sekolah untuk memberikan suatu kepuasan terhadap siswa, karena akan terciptanya kesesuain antara apa yang diharapan dan dibutuhkan siswa dengan realisasi yang diberikan. Berkurangnya pendaftar siswa baru dan berpindahnya siswa lama ke sekolah lain menjadi salah satu malasah yang dihadapi oleh pihak sekolah pada 2 tahun belakangan. Untuk mengetahui dan menentukan tingkat kepuasan siswa terhadap pelayanan yang diberikan oleh pihak sekolah. Bahan (data) dan Metode: data yang diolah adalah data hasil pengisian angket yang dilakukan oleh siswa sekolah MTs.S Nurul Amaliyah tahun 2018. Selanjutnya data hasil pengisisan angket tersebut akan dilakukan proses klasterisasi berdasarkan tingkat kepuasan menggunakan teknik data mining dengan Algoritma K-Means. Hasil klasterisasi dari penilaian siswa ini dapat diketahui bahwa berapa banyak siswa yang merasa sangat puas, cukup puas dan tidak puas terhadap kualitas pelayanan yang diberikan oleh pihak sekolah. Dari hasil klasterisasi yang dilakukan dapat dilihat jumlah siswa yang puas dan tidak puas dengan pelayanan yang diberikan. Sehingga pihak sekolah dapat melakukan peningkatan pada bidang pelayanan untuk mendapatkan tingkat kepuasan yang lebih baik.
\end{abstract}

Kata Kunci: Data Mining K-Means Kualitas Pelayanan

\section{PENDAHULUAN}

Sekolah Madrasah Tsanawiyah Swasta Nurul Amaliyah merupakan salah satu lembaga pendidikan. Sekolah dikelola dengan kepentingan akademik yang terdiri dari siswa, tenaga pengajar dan pegawai. Siswa merupakan komponen masukan dalam sistem pendidikan yang selanjutnya diproses dalam proses pembelajaran sehingga menjadi manusia yang berkualitas sesuai dengan tujuan Pendidikan Nasional. Memberikan pelayanan terbaik adalah salah satu cara sekolah untuk memberikan suatu kepuasan terhadap siswa, karena akan terciptanya kesesuain antara apa yang diharapkan dan dibutuhkan siswa dengan kenyataan yang diberikan untuk mencapai sebuah kepuasan. Kualitas adalah Suatu standar yang harus dicapai oleh seseorang atau kelompok atau lembaga atau organisasi mengenai kualitas sumber daya manusia, kualitas cara kerja, proses dan hasil kerja atau produk yang berupa barang dan jasa [1]. 
Karena kepuasan siswa merupakan salah satu prioritas pada sekolah Madrasah Tsanawiyah Swasta (MTs.S) Nurul Amaliyah. Terjadinya pengurangan pendaftar siswa baru dan beberapa perpindahan siswa ke sekolah lain dapat menyebabkan menurunnya citra sekolah di hadapan masyarakat. Berkurangnya pendaftar siswa baru juga dapat berdampak pada kelangsungan sekolah tersebut karena berkurangnya nilai kepercayaan masyarakat kepada sekolah tersebut.

Pelayanan terhadap siswa ditentukan dari beberapa aspek yaitu pengajar, fasilitas, lokasi, konseling dan keamanan. Untuk mengukur tingkat kepuasan siswa terhadap pelayanan sekolah dapat dilakukan dengan ilmu Data Mining. Tugas Data Mining dibagi menjadi dua yaitu eskriptif dan prediktif. Di mana untuk Fungsi utama Data Mining adalah klasifikasi, penilaian, prediksi, pengelompokan relevansi atau peraturan asosiasi, pengelompokan, deskripsi dan visualisasi [2].

Penerapan Algoritma K-Means dapat membantu pihak sekolah untuk menganalisa data yang besar dan mengetahui tingkat kepuasan siswa dalam pelayanan melalui pengelompokan data hasil pengisian kuesioner dengan cepat dan efisien. Data yang diperoleh dari hasil pengisian kuesioner oleh siswa akan dilakukan menjadi beberapa cluster. Clustering membagi kumpulan data menjadi kelompok terkait sehingga semua kelompok tidak memiliki kesamaan [3].

\section{METODE PENELITIAN}

Penelitian kali ini dilakukan dengan cara melakukan pengamatan langsung ke MTs.S Nurul Amaliyah. Masalah yang diidentifikasi dalam penelitian ini adalah kesulitan dalam menentukan tingkat kepuasan siswa terhadap pelayanan yang diberikan oleh pihak sekolah MTs.S Nurul Amaliyah. Selain pengamatan, juga dilakukan wawancara kepada pihak-pihak yang terkait dengan penelitian ini. Di samping itu juga, melakukan pengambilan sampel data yang dilakukan dengan membagikan angket kepada siswa yang berisi tentang kriteria pelayanan sekolah.

Data yang diperoleh, selanjutnya dianalisis guna menghasilkan informasi yang berguna. Cara ini diharapkan akan menghasilkan pola keputusan yang terbaik sehingga tujuan dari penelitian ini akan dapat tercapai. Data yang telah dianalisa, selanjutnya data tersebut dirancang untuk mendapatkan pemodelan data menggunakan metode K-Means.

\section{ANALISA DAN HASIL}

Pada bab ini merupakan sebuah gambaran proses analisa suatu masalah yang terjadi dan penerapan dari metode atau algoritma yang digunakan untuk memecahkan masalah yang sedang dihadapi. Untuk membantu analisis data dalam pencarian pengetahuan (knowledge), maka akan dilakukan transformasi data yang terdapat pada data hasil pengisisan kuesioner yang telah diisi oleh siswa/i MTs.S Nurul Amaliyah ke dalam bentuk file program pengolah angka (spreadsheat).

\subsection{Pengumpulan Data}

Pengumpulan data dilakukan dengan cara peninjauan langsung ke sekolah MTs.S Nurul Amaliyah. Selain itu meminta data hasil dari pengisian kuesioner siswa yang sebelumnya telah 
dibagikan kepada siswa sebanyak 80 orang pada bulan Desember 2017. Berikut ini adalah sampel data dari pengisian kuesioner penilaian terhadap pelayanan sekolah oleh siswa.

Tabel 1 Data Pengisisan Angkat Siswa

\begin{tabular}{|c|l|c|c|c|c|c|}
\hline Alt & \multicolumn{1}{|c|}{ NAMA } & V1 & V2 & V3 & V4 & V5 \\
\hline P1 & AGENG PANGESTU & 10 & 10 & 8 & 8 & 10 \\
\hline P2 & BIMA ANGGARA PUTRA & 8 & 6 & 8 & 8 & 8 \\
\hline P3 & DANDI SETIAWAN & 8 & 8 & 8 & 8 & 10 \\
\hline P4 & DANU ARYA PUTRA & 8 & 10 & 6 & 8 & 8 \\
\hline P5 & DENY ARIFIN & 6 & 8 & 8 & 8 & 6 \\
\hline P6 & DENNY PRAMANA & 6 & 6 & 6 & 6 & 8 \\
\hline P7 & DONNI ARFIANDA & 6 & 8 & 6 & 8 & 6 \\
\hline P8 & ILHAM TRIADI & 8 & 8 & 6 & 6 & 6 \\
\hline P9 & M. ARI SABANA & 10 & 10 & 8 & 8 & 10 \\
\hline P10 & M. JAMIE AZRARY HASBI & 8 & 6 & 8 & 8 & 8 \\
\hline P11 & MHD. IQBAL ANANDA & 6 & 6 & 6 & 8 & 6 \\
\hline P12 & MISWANTO & 10 & 10 & 8 & 8 & 10 \\
\hline P13 & MUHAMMAD ADAM QODAPI & 10 & 10 & 8 & 8 & 10 \\
\hline P14 & MUHAMMAD AMNAR PRATAMA & 8 & 10 & 6 & 8 & 8 \\
\hline P15 & MUHAMMAD HARI MULIA WARMAN & 10 & 10 & 8 & 8 & 10 \\
\hline P16 & MUHAMMAD JOGHI & 8 & 10 & 6 & 8 & 8 \\
\hline P17 & MUHAMMAD NAUFAL ALFALAH & 10 & 10 & 8 & 8 & 10 \\
\hline P18 & MUHAMMAD RASYID TRIADI & 10 & 10 & 8 & 8 & 10 \\
\hline P19 & NAUFAL MAHMUDA & 10 & 10 & 8 & 8 & 10 \\
\hline P20 & NIKY JERIANSYAH & 4 & 8 & 6 & 8 & 8 \\
\hline P21 & PEPRI HERI YADI & 8 & 10 & 6 & 8 & 8 \\
\hline P22 & PERIAYOGA & 10 & 10 & 8 & 8 & 10 \\
\hline$\ldots$ & $\ldots$ & $\ldots$ & $\ldots$ & $\ldots$ & $\ldots$ & $\ldots$ \\
\hline P80 & SHAIRA AZRARY HASBI & 8 & 10 & 6 & 8 & 8 \\
& & & & & & \\
\hline & & & & \\
\hline
\end{tabular}

Tabel 1 Merupakan data nilai kuesioner yang telah diisi oleh siswa MTs.S Nurul Amaliyah pada tahun 2018.

Tabel 2 Atribut

\begin{tabular}{|l|l|}
\hline Atribut & Variabel \\
\hline Pengajar & V1 \\
\hline Fasilitas & V2 \\
\hline Konseling & V3 \\
\hline Lokasi & V4 \\
\hline Keamanan & V5 \\
\hline
\end{tabular}

J-SISKO TECH Vol. 2, No.2 Juli , 2019: 118-125 
Tabel 2 merupakan data atribut yang akan digunakan dalam melakukan penilaian pada pelayanan sekolah.

Tabel 3 Nilai Bobot

\begin{tabular}{|l|l|}
\hline Atribut & Nilai \\
\hline Sangat Baik & 10 \\
\hline Baik & 8 \\
\hline Cukup & 6 \\
\hline Kurang Baik & 4 \\
\hline Sangat Kurang & 2 \\
\hline
\end{tabular}

Tabel 3 merupakan nilai Bobot yang akan digunakan dalam melakukan penilaian pada pelayanan sekolah.

Tabel 4 Nilai Centroid

\begin{tabular}{|c|c|c|c|c|c|c|}
\hline No & Centroid & K1 & K2 & K3 & K4 & K5 \\
\hline 1. & M1 & 9.23 & 9.85 & 7.31 & 8.69 & 9.23 \\
\hline 2. & M2 & 6.27 & 6.45 & 6.64 & 7.09 & 7.27 \\
\hline 3. & M3 & 4.83 & 4.33 & 3.67 & 4.33 & 4.67 \\
\hline
\end{tabular}

Tabel 4 merupakan nilai centroid awal yang akan digunakan dalam melakukan penelitian pada pelayanan sekolah.

\subsection{Penerapan Algoritma K-Means}

1. Menentukan Jumlah Cluster

Berdasarkan data diatas Cluster yang akan dibentuk sebanyak 3 cluster. Dengan ketentuan cluster 0 untuk siswa yang memiliki penialaian kurang baik, cluster 1 untuk siswa yang memberi nilai cukup baik dan cluster 2 uintuk siswa yang memberi nilai baik.

2. Menentukan Pusat Cluster

Setelah menentukan jumlah cluster yang terbentuk sebanyak 3 (tiga), tentukan pusat (cluster). Untuk centroid awal dipilih secara acak berdasarkan data yang ada. Berikut centroid yang terpilih pada tabel 4.

3. Menghitung Jarak

Pada tahap ini dilakukan perhitungan jarak pada setiap variabel pada sampel data terhadap pusat cluster yang sudah ditentukan.

a. Dengan Centroid M1 $(9.23,9.85,7.31,8.69,9.23)$

1. Jarak antara P1 dengan titik M1

$=\sqrt{\sum_{i=1}^{n}\left(x_{i}-y_{i}\right)^{2}}$ 


$$
\begin{aligned}
& =\sqrt{(10-9.23)^{2}+(10-9.85)^{2}+(8-7.31)^{2}+(8-8.69)^{2}+(10-9.23)^{2}} \\
& =1.47
\end{aligned}
$$

Lakukan perhitungan sampai P80.

b. Dengan Centroid M2 (6.27, 6.45, 6.64, 7.09,7.27)

1. Jarak antara $P 1$ dengan titik $M 2$

$$
\begin{aligned}
& =\sqrt{\sum_{i=1}^{n}\left(x_{i}-y_{i}\right)^{2}} \\
& =\sqrt{(10-6.27)^{2}+(10-6.45)^{2}+(8-6.64)^{2}+(8-7.09)^{2}+(10-7.27)^{2}} \\
& =6.05
\end{aligned}
$$

Lakukan perhitungan sampai P80.

c. Dengan Centroid M3 $(4.83,4.33,3.67,4.33,4.67)$

1. Jarak antara $\mathrm{P} 1$ dengan titik $\mathrm{M} 3$

$$
\begin{aligned}
& =\sqrt{\sum_{i=1}^{n}\left(x_{i}-y_{i}\right)^{2}} \\
& =\sqrt{(10-4.83)^{2}+(10-4.33)^{2}+(8-3.67)^{2}+(8-4.33)^{2}+(10-4.67)^{2}} \\
& =10.39
\end{aligned}
$$

Lakukan perhitungan sampai P80.

Tabel 5 Hasil Perhitungan Jarak Pada Setiap Variabel

\begin{tabular}{|c|c|c|c|c|c|c|}
\hline No. & Alt & Jarak ke titik M1 & Jarak ke titik M2 & Jarak ke titik M3 & Kedekatan & Keterangan \\
\hline 1 & P1 & 1,47 & 6,05 & 10,93 & 1,47 & C2 \\
\hline 2 & P3 & 2,54 & 3,94 & 9,17 & 2,54 & C2 \\
\hline 3 & P4 & 2,29 & 4,16 & 8,49 & 2,29 & C2 \\
\hline 4 & P9 & 1,47 & 6,05 & 10,93 & 1,47 & C2 \\
\hline 5 & P12 & 1,47 & 6,05 & 10,93 & 1,47 & C2 \\
\hline 6 & P13 & 1,47 & 6,05 & 10,93 & 1,47 & C2 \\
\hline 7 & P14 & 2,29 & 4,16 & 8,49 & 2,29 & C2 \\
\hline 8 & P15 & 1,47 & 6,05 & 10,93 & 1,47 & C2 \\
\hline 9 & P16 & 2,29 & 4,16 & 8,49 & 2,29 & C2 \\
\hline 10 & P17 & 1,47 & 6,05 & 10,93 & 1,47 & C2 \\
\hline 11 & P18 & 1,47 & 6,05 & 10,93 & 1,47 & C2 \\
\hline 12 & P19 & 1,47 & 6,05 & 10,93 & 1,47 & C2 \\
\hline 13 & P21 & 2,29 & 4,16 & 8,49 & 2,29 & C2 \\
\hline 14 & P22 & 1,47 & 6,05 & 10,93 & 1,47 & C2 \\
\hline 15 & P23 & 1,47 & 6,05 & 10,93 & 1,47 & C2 \\
\hline 16 & P24 & 2,29 & 4,16 & 8,49 & 2,29 & C2 \\
\hline 17 & P26 & 1,47 & 6,05 & 10,93 & 1,47 & C2 \\
\hline 18 & P27 & 2,29 & 4,16 & 8,49 & 2,29 & C2 \\
\hline 19 & P29 & 1,47 & 6,05 & 10,93 & 1,47 & C2 \\
\hline 20 & P30 & 1,84 & 6,65 & 11,75 & 1,84 & C2 \\
\hline 21 & P31 & 1,47 & 6,05 & 10,93 & 1,47 & C2 \\
\hline
\end{tabular}

J-SISKO TECH Vol. 2, No.2 Juli , 2019 : 118-125 


\begin{tabular}{|c|c|c|c|c|c|c|}
\hline 22 & P32 & 1,84 & 6,65 & 11,75 & 1,84 & $\mathrm{C} 2$ \\
\hline 23 & P33 & 2,29 & 4,16 & 8,49 & 2,29 & $\mathrm{C} 2$ \\
\hline 24 & P34 & 1,84 & 6,65 & 11,75 & 1,84 & $\mathrm{C2}$ \\
\hline 25 & P35 & 3,14 & 3,84 & 8,49 & 3,14 & $\mathrm{C} 2$ \\
\hline 26 & P36 & 1,84 & 6,65 & 11,75 & 1,84 & $\mathrm{C} 2$ \\
\hline 27 & P41 & 1,84 & 6,65 & 11,75 & 1,84 & $\mathrm{C} 2$ \\
\hline 28 & P44 & 1,84 & 6,65 & 11,75 & 1,84 & C2 \\
\hline 29 & P45 & 1,84 & 6,65 & 11,75 & 1,84 & $\mathrm{C} 2$ \\
\hline 30 & P47 & 1,84 & 6,65 & 11,75 & 1,84 & $\mathrm{C} 2$ \\
\hline 31 & P50 & 1,84 & 6,65 & 11,75 & 1,84 & $\mathrm{C} 2$ \\
\hline 32 & P51 & 1,84 & 6,65 & 11,75 & 1,84 & $\mathrm{C} 2$ \\
\hline 33 & P52 & 2,29 & 4,16 & 8,49 & 2,29 & $\mathrm{C} 2$ \\
\hline 34 & P55 & 2,29 & 4,16 & 8,49 & 2,29 & $\mathrm{C} 2$ \\
\hline 35 & P58 & 1,84 & 6,65 & 11,75 & 1,84 & $\mathrm{C} 2$ \\
\hline 36 & P59 & 2,29 & 4,16 & 8,49 & 2,29 & $\mathrm{C} 2$ \\
\hline 37 & P60 & 1,84 & 6,65 & 11,75 & 1,84 & $\mathrm{C} 2$ \\
\hline 38 & P62 & 1,84 & 6,65 & 11,75 & 1,84 & $\mathrm{C2}$ \\
\hline 39 & P63 & 3,64 & 4,46 & 8,53 & 3,64 & $\mathrm{C} 2$ \\
\hline 40 & P64 & 2,29 & 4,16 & 8,49 & 2,29 & $\mathrm{C} 2$ \\
\hline 41 & P65 & 1,84 & 6,65 & 11,75 & 1,84 & C2 \\
\hline 42 & P66 & 1,84 & 6,65 & 11,75 & 1,84 & $\mathrm{C} 2$ \\
\hline 43 & P67 & 2,72 & 2,93 & 8,17 & 2,72 & $\mathrm{C} 2$ \\
\hline 44 & P68 & 1,84 & 6,65 & 11,75 & 1,84 & $\mathrm{C} 2$ \\
\hline 45 & P70 & 2,29 & 4,16 & 8,49 & 2,29 & $\mathrm{C} 2$ \\
\hline 46 & P71 & 1,84 & 6,65 & 11,75 & 1,84 & $\mathrm{C} 2$ \\
\hline 47 & P72 & 2,29 & 4,16 & 8,49 & 2,29 & $\mathrm{C2}$ \\
\hline 48 & P75 & 2,29 & 4,16 & 8,49 & 2,29 & $\mathrm{C} 2$ \\
\hline 49 & P77 & 2,29 & 4,16 & 8,49 & 2,29 & $\mathrm{C} 2$ \\
\hline 50 & P78 & 1,84 & 6,65 & 11,75 & 1,84 & $\mathrm{C} 2$ \\
\hline 51 & P79 & 2,29 & 4,16 & 8,49 & 2,29 & $\mathrm{C2}$ \\
\hline 52 & P80 & 2,29 & 4,16 & 8,49 & 2,29 & $\mathrm{C} 2$ \\
\hline 53 & P2 & 4,33 & 2,53 & 7,49 & 2,53 & $\mathrm{C} 1$ \\
\hline 54 & P5 & 5,02 & 2,60 & 6,99 & 2,60 & C1 \\
\hline 55 & P6 & 5,98 & 1,55 & 4,84 & 1,55 & $\mathrm{C} 1$ \\
\hline 56 & P7 & 5,15 & 2,31 & 5,96 & 2,31 & $\mathrm{C} 1$ \\
\hline 57 & P8 & 4,93 & 2,93 & 5,79 & 2,93 & $\mathrm{C} 1$ \\
\hline 58 & P10 & 4,33 & 2,53 & 7,49 & 2,53 & C1 \\
\hline 59 & P11 & 6,15 & 1,77 & 4,98 & 1,77 & C1 \\
\hline 60 & P20 & 5,87 & 3,05 & 6,64 & 3,05 & C1 \\
\hline 61 & P25 & 7,77 & 3,17 & 5,18 & 3,17 & C1 \\
\hline 62 & P28 & 5,79 & 3,34 & 5,37 & 3,34 & $\mathrm{C} 1$ \\
\hline 63 & P37 & 5,38 & 1,43 & 5,84 & 1,43 & $\mathrm{C} 1$ \\
\hline 64 & P38 & 7,57 & 2,99 & 4,71 & 2,99 & C1 \\
\hline
\end{tabular}




\begin{tabular}{|l|l|l|l|l|l|l|}
\hline 65 & P39 & 6,68 & 2,93 & 6,84 & 2,93 & C1 \\
\hline 66 & P40 & 5,77 & 2,38 & 4,98 & 2,38 & C1 \\
\hline 67 & P42 & 7,73 & 4,58 & 6,34 & 4,58 & $\mathrm{C} 1$ \\
\hline 68 & P43 & 6,18 & 2,93 & 5,37 & 2,93 & $\mathrm{C} 1$ \\
\hline 69 & P48 & 7,08 & 3,28 & 4,91 & 3,28 & $\mathrm{C} 1$ \\
\hline 70 & P53 & 5,38 & 1,43 & 5,84 & 1,43 & $\mathrm{C} 1$ \\
\hline 71 & P56 & 4,33 & 2,53 & 7,49 & 2,53 & $\mathrm{C} 1$ \\
\hline 72 & P57 & 6,42 & 3,65 & 7,62 & 3,65 & $\mathrm{C} 1$ \\
\hline 73 & P61 & 6,00 & 3,44 & 5,18 & 3,44 & $\mathrm{C} 1$ \\
\hline 74 & P69 & 4,33 & 2,53 & 7,49 & 2,53 & $\mathrm{C} 1$ \\
\hline 75 & P46 & 8,28 & 4,29 & 2,48 & 2,48 & $\mathrm{C} 0$ \\
\hline 76 & P49 & 7,83 & 3,40 & 2,73 & 2,73 & $\mathrm{C} 0$ \\
\hline 77 & P54 & 10,35 & 5,48 & 2,03 & 2,03 & $\mathrm{C} 0$ \\
\hline 78 & P73 & 12,03 & 7,40 & 2,61 & 2,61 & $\mathrm{C} 0$ \\
\hline 79 & P74 & 13,83 & 9,16 & 4,02 & 4,02 & $\mathrm{C} 0$ \\
\hline 80 & P76 & 9,38 & 4,92 & 1,86 & 1,86 & $\mathrm{C} 0$ \\
\hline
\end{tabular}

Berdasarkan hasil perhitungan jarak variabel pada centroid baru maka masing-masing cluster memiliki anggota sebagai berikut,

1. C2 memiliki jumlah anggota sebanyak 52 orang

2. $\quad$ C1 memiliki jumlah anggota sebanyak 22 orang

3. $\quad \mathrm{C} 0$ memiliki jumlah anggota sebanyak 6 orang

Berdasarkan perhitungan dan pengelompokan data pada tabel 4.13 menggunakan algoritma K-Means sebanyak 3 iterasi dan 80 responden. Maka didapatkan hasil pada cluster 2 sebanyak 52 orang memiliki penilaian puas terhadap pelayanan yang diberikan, pada cluster 1 sebanyak 22 orang merasa cukup dan pada cluster 3 terdapat 6 orang yang memiliki penilaian kurang baik. Berdasarkan jumlah siswa tersebut maka sebanyak $65 \%$ siswa merasa puas terhadap pelayanan, 27,5 merasa cukup dan $7,5 \%$ merasa kurang puas.

\section{KESIMPULAN}

Berdasarkan hasil analisis dan pengujian terhadap nilai pelayanan sekolah MTs.S Nurul Amaliyah kepada siswa maka dapat diambil kesimpulan bahwa, Penerapan Data Mining menggunakan algoritma K-Means dapat digunakan dalam membuat cluster data dalam menentukan tingkat kepuasan siswa, puas, cukup dan kurang puas berdasarkan kuesioner yang disebar sehingga dapat diketahui bahwa,

a. Siswa yang memberi penilaian puas sebanyak 52 orang.

b. Siswa yang memberi penilaian cukup sebanyak 22 orang

c. Siswa yang memberi penilaian kurang puas sebanyak 6 orang

\section{UCAPAN TERIMA KASIH}

Puji Syukur kepada Allah SWT atas rahmat dan rezeky yang telah diberikan. Terima kasih kepada seluruh keluarga atas dukungan yang telah diberikan kepada saya dalam

J-SISKO TECH Vol. 2, No.2 Juli , 2019: 118-125 
melakukan penelitian. Dan terima kasih kepada seluruh guru dan pegawai sekolah MTs.S Nurul Amaliyah atas waktu dan kesempatan yang telah diberikan kepada saya untuk melakukan penelitian pada sekolah tersebut.

\section{REFERENSI}

Y. R. Wulan "Pengaruh Kualitas Pelayanan, Promosi Dan Suku Bunga Kredit Terhadap Kepuasan Nasabah Usaha Mikro Kecil Dan Menengah (Umkm) Di Pt. Bank Rakyat Indonesia (Persero) Tbk. Unit Tingkir Salatiga", 2016.

[1] J. Wang, et al, "The Application of Data Mining Technology to BigDat", 2017.

I. A. Venkatkumar, and S. J. K. Shardaben, "Comparative study of Data Mining Clustering algorithms", 2016. 